•综述・

\title{
水稻驯化与长江文明
}

\author{
宋志平 ${ }^{*}$ 陈家宽 $^{1}$ 赵 耀 $^{2}$ \\ 1 (生物多样性与生态工程教育部重点实验室, 复旦大学生物多样性科学研究所, 上海 200438) \\ 2 (南昌大学生命科学研究院流域生态学研究所, 南昌 330031)
}

\begin{abstract}
摘要: 水稻(即亚洲栽培稻Oryza sativa)是世界上最重要的粮食作物之一, 全球有超过半数以上人口以稻米为食。 关于水稻是何时、何地、在什么环境下开始驯化等问题一直是学术界关注的热点。得益于分析技术的进步, 近年 来考古学和遗传学研究在水稻驯化起源问题上取得了重要进展。本文简要综述了有关长江流域的水稻驯化起源的 遗传学和考古学的研究进展, 并讨论了水稻驯化与稻作文化及长江文明的关系。遗传学研究结果认为水稻(粳稻) 最早起源于中国长江流域及以南地区(珠江流域), 考古学证据则表明水稻最先于10,000-8,000 BP在中国长江流域 被驯化, 水稻驯化和稻作农业的发展催生了长江文明。这些进展促进了我们对水稻驯化、稻作文化和长江文明的 认识, 对长江流域重要植物资源的保护也有启示意义。
\end{abstract}

关键词: 栽培稻; 野生稻; 驯化; 长江文明; 起源

\section{Rice domestication and the Yangtze River civilization}

\author{
Zhiping Song ${ }^{1 *}$, Jiakuan Chen ${ }^{1}$, Yao Zhao ${ }^{2}$ \\ 1 Ministry of Education Key Laboratory for Biodiversity Science and Ecological Engineering, Institute of Biodiversity \\ Science, Fudan University, Shanghai 200438 \\ 2 Center for Watershed Ecology, Institute of Life Science and Key Laboratory of Poyang Lake Environment and Resource \\ Utilization, Ministry of Education, Nanchang University, Nanchang 330031
}

\begin{abstract}
Rice (Oryza sativa) is one of the most important crops in the world and serves as a staple food source for more than half of the world's population. Research into when, where, and how rice was initially cultivated and eventually domesticated is essential. Research on these questions has been greatly advanced recently, along with nearly continuous research in both genetics and archaeology using newly developed analytical techniques. Here, we review the scientific understanding of rice domestication in the Yangtze River valley from both an archaeological and genetic perspective, and discuss the relationship between rice domestication and the Yangtze River civilization. Recent genetic research suggests that domesticated rice (O. sativa ssp. japonica) first occurred in southern China, including the Yangtze River valley and the Pearl River Basin. Current findings from archaeology support the view that $O$. sativa ssp. japonica was firstly domesticated in the Yangtze River valley ca.10,000-8,000 BP, and rice cultivation and agricultural development triggered the Yangtze River civilization. These findings enhance our understanding of rice domestication and related cultivation culture and also have implications for conservation of plant resources in the Yangtze River valley.
\end{abstract}

Key words: cultivated rice; wild rice; domestication; the Yangtze River civilization; origin

植物的驯化与利用催生了农耕文明。农耕文明 的起源与发展, 促进了工具的运用与不断改良, 转 变了人类的生活方式, 促使人类由迁徙转变为定居, 出现聚落、城邦及相应的社会组织结构, 为人类文 明的发展奠定了基础。中华文明(或华夏文明)是世
界上唯一一直传承的古老文明。考古证据显示, 长 江流域(总体位于24-35 $\mathrm{N}$ 之间)有着和黄河流域一 样辉煌的史前文明, 两者都是中华文明之源; 长江 文明以稻作文明为内核, 黄河文明则以粟作文明为 其鲜明特征(Barton et al, 2009; Zhao, 2011)。

收稿日期: 2018-01-16; 接受日期: 2018-04-16

* 通讯作者 Author for correspondence. E-mail: songzp@fudan.edu.cn 
水稻(即亚洲栽培稻Oryza sativa)是世界上最重 要的粮食作物之一, 目前全球有超过半数以上人口 以稻米为食。水稻起源于野生稻。先人从对野生稻 的原始照看到有意识的栽培管理, 再到有目的的选 育, 最终驯化出适应栽培环境的栽培稻, 并广泛栽 培而形成稻作农业, 经过了长达数千年的发展历程 (赵志军, 2009)。在此过程中, 一方面, 野生稻原有 的一些性状经过人工选择, 逐渐发生适应于栽培环 境的改变, 形成驯化性状(domesticated traits), 最终 演变为栽培稻; 另一方面, 因适应水稻栽培管理的 需要, 人们不断改进生产工具, 变革生产方式, 从 最早的刀耕水㱹农业到耜耕农业、再到犁耕农业, 逐步确立了长江流域以稻作为主要生产方式的农 耕文明。

水稻驯化及稻作农业为长江文明的发展和繁 荣提供了重要的物质和文化基础, 也是长江文明为 人类做出的巨大的开创性贡献(Larson et al, 2014)。 关于水稻是何时、何地、在什么环境下开始驯化等 问题一直是国际学术界关注的热点。得益于新技术 手段的不断运用, 越来越多的考古学和遗传学研究 结果显示, 中国最早开始利用水稻, 长江流域及以 南地区是水稻的驯化起源地(Cross \& Zhao, 2014)。 本文简要评述了近年来有关水稻起源的考古学和 遗传学研究进展, 特别关注长江流域的相关研究, 分析了各种研究的结论不一致的可能原因, 并讨论 了未来值得深入研究的科学问题。

\section{水稻关键驯化性状及相关基因}

稻属包含 2 个栽培种和 20 多个野生种, 栽培种 分别为亚洲栽培稻( $(O$. sativa $)$ 和非洲栽培稻 $(O$. glaberrima) (Vaughan et al, 2003, 2008b)。我们通常所称 的水稻是指亚洲栽培稻。与水稻遗传关系最近的是 普通野生稻(O. rufipogon)和尼瓦拉野生稻(O.nivara) (Vaughan et al, 2008a), 它们广泛分布在南亚 和东南亚以及中国部分地区的永久性或季节性湿 地中(Fuller et al, 2010)。普通野生稻为多年生, 对光 周期敏感, 异交率较高; 尼瓦拉野生稻则是一年生, 对光周期不敏感, 自交率比较高(Vaughan et al, 2008a)。这两种野生稻虽然有明显的遗传分化(Liu et al, 2015), 但它们遗传上都与水稻关系密切, 以 至于究竟谁是水稻的直接祖先种存在争议。目前广 泛支持普通野生稻是水稻的祖先种(Khush, 1997;
Castillo et al, 2016)。

因适应不同栽培区的气候和环境条件，水稻分 化形成了不同的亚种或生态型, 其中最重要的两个 亚种是粳稻(O. sativa ssp. japonica)和籼稻(O. sativa ssp. indica), 其次还有aus稻和香稻(aromatic) (Garris et al, 2005; Caicedo et al, 2007; Vaughan et al, 2008b; McNally et al, 2009)。粳稻主要分布于东亚的 亚热带地区、东南亚的高原和南亚高地，而籼稻则 主要集中在亚洲的热带地区。水稻驯化起源问题实 际上还牵涉到不同栽培亚种, 特别是籼稻和粳稻的 起源分化(indica-japonica differentiation)问题(王象 坤, 1996; Kovach et al, 2007), 因而愈发扑朔迷离。

理论上，通过分析野生稻的地理和生态分布格 局、历史气候变化对野生稻分布格局的影响以及野 生种群与栽培稻的遗传关系，就可以推测栽培稻起 源地。水稻最初的驯化事件必然发生在先民能够直 接利用野生种群的地区，具有野生稻分布是确定水 稻起源地的先决条件(Fuller et al, 2010)。然而，野生 稻的现代分布格局是历史气候变化和人类土地利 用活动共同影响的结果，与历史分布存在差异。野 生稻的自然分布一般集中在热带和亚热带，对温 度、湿度均有较高要求。普通野生稻的现代最北缘 分布为我国江西省东乡县 $\left(28^{\circ} 14^{\prime} \mathrm{N}\right)$, 但基于古气 候、地形学和花粉数据重建古植被的研究结果显示, 野生稻可能曾在长江流域和华东地区具有广泛分 布，最北到达山东(Huang \& Schaal, 2012; Zhao et al, 2013)。谱系地理学研究结果提示, 历史上, 在更新 世冰期干旱气候期间, 普通野生稻种群退缩到湿热 的避难所，如印度东部、云南和东南亚等区域 (Londo et al, 2006)。普通野生稻种群最近的地理扩 张发生在大约16,500-15,000 BP的冰后期，当时的 气候变得湿暖, 而且 $\mathrm{CO}_{2}$ 浓度迅速从18 Pa (atmospheric partial pressure)上升到 $27 \mathrm{~Pa}$, 这对植物特别 是 $\mathrm{C}_{3}$ 植物水稻的光合效率和生物量生产有重要影 响(Fuller et al, 2010)。新仙女木时代(Younger Dryas, 13,000-11,500 BP)气候急剧变冷, 迫使普通野生稻 向南退缩(Kovach et al, 2007)。随后，随着栽培稻的 驯化与推广种植, 以及唐宋时期(1,200-1,000 BP)的 气候又一次变冷, 普通野生稻的原生生境进一步减 少和向南退缩, 最终形成现在的分布格局(Zhao et al, 2013)。此外，考古资料还证实，距今 10,000 年前 (栽培稻开始驯化时间), 普通野生稻是长江流域的 
习见物种(Fuller, 2007; Zong et al, 2007; Zuo et al, 2017)。因此，虽然当前长江流域仅在江西东乡县、 湖南茶陵县和江永县等地有少量普通野生稻种群, 但栽培稻依然可能起源于此区域(Choi et al, 2017)。

在人类栽培过程中, 植物逐渐发生关键的形态 (和遗传)改变, 以适应栽培环境, 在性状上表现出 驯化适应性综合征(adaptive syndrome of domestication), 包括更加紧凑的株型、花序增大且小花数目 增多、果实或种子变大、落粒性减弱, 以及种子休 眠性降低等(Hammer, 1984)。从普通野生稻到栽培 稻的转变过程中, 野生稻逐渐失去了多年生、落粒 性、长芒、匍匐生长等特征, 成为依赖人工种植的 栽培稻。落粒性、休眠性和株型等性状是水稻驯化 的关键性状, 种皮颜色、籽粒形态等性状也与水稻 驯化密切相关(Fuller et al, 2010; Sakuma et al, 2011; 区树俊等, 2012)。

不落粒作为农作物驯化的关键性状, 是区分栽 培种及其野生祖先的最主要依据之一(Jones \& Liu, 2009)。普通野生稻的籽粒成熟时, 护颖和小穗轴的 接合处(小穗基盘)一般会形成离层, 这使得种子易 于脱落与传播, 但不利于种子的收获; 栽培稻小穗 基盘的离层发育不完全, 成熟种子需借助外力才能 脱粒，从而有利于稻谷的收获(Li et al, 2006)。因此, 普通野生稻小穗基盘光滑, 而栽培稻粗粘(Fuller, 2007)。小穗轴是植物考古中通过浮选法相对容易获 得的水稻实物遗存之一, 因而小穗基盘的形态业已 成为判断古稻类型的重要依据之一(如Fuller et al, 2009)。落粒性是数量遗传性状(QTL), 遗传学研究 先后确定了多个与此性状有关的QTL位点, 如 sh-h、sh4、qsh1等(Konishi et al, 2006; Li et al, 2006)。 其中 sh4 和 $q s h 1$ 是控制水稻落粒的主要基因(Zhang et al, 2009)。sh4为一个隐性突变, 是广泛存在于所 有栽培稻(粳稻、籼稻、香稻和aus稻)的 4 号染色体 上的一个基因的SNP, 会导致离层发育不完全( $\mathrm{Li}$ et al, 2006)。sh4是与栽培稻驯化起源关联的主要突变 (Sang \& Ge, 2007; Fuller et al, 2009)。分子系统学研 究显示, 粳稻和籼稻的 $s h 4$ 基因位于同一进化支上, 暗示该基因是通过一次驯化保留到基因组上，这被 认为是水稻单次起源或者籼粳分化出现在水稻驯 化之后的最有力证据(Lin et al, 2007; Molina et al, 2011)。qsh1主要存在于温带粳稻中(Konishi et al, 2006), 是在促使东亚水稻向温带粳稻分化的遗传
瓶颈过程中或者之后被固定下来的(Zhang et al, 2009)。

粒形是另一个重要驯化性状。古人在栽培植物 过程中, 逐渐意识到粒形是产量性状，开始对大粒 形种子进行有意识的选择。水稻粒形(谷粒大小)是 重要的产量和品质农艺性状，是水稻驯化过程中最 突出的生物学特征变化之一(Fuller et al, 2008)。一 般情况下, 普通野生稻的种子粒形为细长形且附有 长芒, 籼稻长圆形或细长形, 而粳稻则为阔卵形或 短圆形(图1)。粒形(包括颖壳)可以较好地区别野生 种与栽培种, 由于稻谷相对容易保存, 出土稻谷遗 存较多, 粒形分析成为研究栽培稻驯化的重要手段 (Fuller, 2007)。水稻粒形也是数量遗传性状，包含粒 长、粒宽和粒厚等指标，其中粒宽更引人注意，其 驯化时间早于粒长(公婷婷, 2017)。水稻全基因组测 序的完成促进了粒宽性状的控制基因的发掘，已有 多个粒宽主效基因被克隆，例如 $q S W 5$ ，该基因在粳 稻群体中受到强烈选择(Shomura et al, 2008)。

水稻株型主要由分莕数、分箵角度、株高和穗 型所决定(Wang \& Li, 2005)。普通野生稻通常分等 多, 分菜角度大而匍匐生长, 散穗型; 栽培稻则分

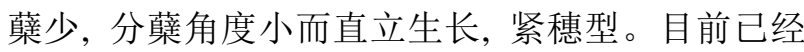
发现多个与株型性状相关的基因(区树俊等，2012), 其中最引人注意的是prog1基因(Jin et al, 2008; Tan et al, 2008)。该基因位于水稻第7号染色体上，编码 具有转录活性的锌指蛋白类转录因子, 在叶腋分生 组织(分藥芽的形成部位)、芽茎尖分生组织和幼叶 中高表达, 控制分菜角度和分菜数, 受到了人工选 择, 使水稻的株型由野生型转变成驯化型(Jin et al, 2008)。另外, “绿色革命” 基因(矮杆基因) $s d 1$ 在水稻 驯化过程中也受到人为驯化选择(Asano et al, 2011), 相对于普通野生稻，栽培稻中 sd1基因序列的遗传 多样性减少了98\% (Paterson \& Li, 2011)。

普通野生稻种子具有较强休眠性，这有利于其 度过不利的生长季节，栽培稻则没有明显的休眠性， 这适应于生产上同步发芽的需要(Cohn et al, 1983; Sweeney \& McCouch, 2007)。普通野生稻的种皮通 常是红色, 而栽培稻多为白色; 野生稻颖壳黑色或 褐黑色，栽培稻多为浅黄色(图1), 这些都与种子休 眠性的差异有关(Seshu \& Dadlani, 1991)。通过分子 遗传学研究，人们已发现了多个与水稻种子休眠相 关的QTL位点(区树俊等, 2012), 其中qSD7-1位点通 
过母体组织(包括颖壳、果皮和种皮)来控制水稻种 子休眠(Gu et al, 2011)。 rc 基因导致水稻白种皮 (Sweeney et al, 2007), 该基因与sh4类似, 起源于粳 稻而后扩散到籼稻(Vaughan et al, 2008b; Cross \& Zhao, 2014)。

\section{水稻起源的分子生物学证据}

分子检测技术的进步极大推动了栽培稻驯化 起源研究。中性标记检测结果显示, 粳稻和籼稻的 遗传分化显著(Garris et al, 2005), 加之它们在形态 上也有明显差异(图1), 这导致通常认为粳稻和籼稻 有不同的起源(多源论)。较早的等位酶分析结果将 普通野生稻分为中国和东南亚两个遗传谱系, 因而 推测粳稻和籼稻分别起源于不同地区 (Second, 1982)。类似地，Sun等(1997)的RFLP检测结果显示， 中国普通野生稻种群偏粳稻, 而东南亚的普通野生 稻种群偏籼稻, 普通野生稻已发生了籼粳分化, 粳 稻和籼稻应是独立起源。随后的分子系统学研究将 粳稻和籼稻的遗传分歧时间估计在0.4-0.2百万年 前(Vitte et al, 2004; Zhu \& Ge, 2005; Tang et al, 2006), 这明显早于考古学研究所估计的水稻驯化 起源时间(大约10,000 BP), 暗示粳、籼稻分别起源 于不同祖先群。进而, Londo等(2006)基于两个核基 因和一个叶绿体基因的序列分析, 认为粳稻大约在 10,000年前起源于中国南方(泛指长江流域及以南 地区), 而籼稻稍晚起源于东印度地区。粳、籼稻分 别起源的观点得到了 Caicedo等(2007)的111个基因 片段分析以及He等(2011)基因组分析的结果的支 持。然而, Gao和Innan (2008)的SSR分析结果不支持 粳、籼稻分别起源的观点。Molina等(2011)同样支 持单起源的观点, 认为栽培稻大约在13,500-8,200 BP起源于中国长江流域。Huang等(2012a)的谱系地 理学研究也支持栽培稻起源于中国的单起源假说, 但认为首先起源的是籼稻而非粳稻。通过对大样本 (446份普通野生稻和1,083份栽培稻)的基因组分析, Huang等(2012b)也支持单起源的观点, 并认为粳稻 最先起源于中国的珠江流域, 这一观点得到Wei等 (2012)的研究结果的支持。但后者一方面支持中国 珠江流域是栽培稻的驯化中心, 另一方面又认为 粳、籼稻为独立起源(Wei et al, 2012)。Civáńn等(2015) 重新分析Huang等(2012b)的基因组数据后认为, 水 稻驯化为多起源, 粳稻、籼稻与aus稻分别起源于不
同地区。最近, Choi等(2017)以及Choi和Purugganan (2018)的基因组研究结果也支持多起源的观点, 认 为粳稻、籼稻、 aus稻分别来自不同祖先群O. rufipogon 或 $O$. nivara, 而且粳稻最先于 $18.3 \mathrm{ka}$ (24.1-13.1 ka)前从分布于中国长江流域的O. rufipogon中驯化出来。

理论上，对驯化相关基因的进化分析可以解决 栽培物种的驯化起源问题, 然而相关研究结果却存 在分歧。关键驯化基因，如落粒性基因sh4，红种皮 基因 $r c$, 株型基因 $p r o g 1$ 的系统重建都指向栽培稻为 中国单起源(Sweeney et al, 2007; Zhang et al, 2009; Choi et al, 2017; Choi \& Purugganan, 2018)。但是, Civáńn和Brown（2017)对这些基因(还包括无芒基因 $L A B A 1$ )及其在基因组上邻近序列进行分析后, 认 为这些驯化基因在野生稻中出现的时间远早于栽 培稻的驯化，暗示不同栽培稻亚种有不同起源。 Singh等(2017)持类似观点。Choi等(2017)以及Choi 和Purugganan (2018)也发现驯化基因起源早于栽培 稻的驯化, 并因此提出了 “多起源/单驯化”假设(the multiple origin/single domestication model)。

纵观有关栽培稻驯化的遗传学和分子进化生 物学研究, 我们初步可以总结如下几点: (1)普通野 生稻O. rufipogon是栽培稻的直接祖先, 一年生野生 稻O. nivara也是栽培稻的祖先种; (2)栽培稻亚种粳 稻和籼稻遗传分化明显，分别于不同的时间起源于 不同的地区(多起源); (3)栽培稻最早起源于中国长 江流域及以南地区(包括珠江流域), 粳稻驯化早于 籼稻; (4)关键驯化基因的起源时间早于栽培稻的驯 化; (5)杂交及基因流在栽培稻(尤其是籼稻)的驯化 起源以及驯化基因的扩散中发挥了重要作用。值得 注意的是，栽培稻自被驯化以来，就一直与野生稻 频繁发生基因交流，存在共进化关系(Song et al, 2006; Zhao et al, 2010; Ge \& Sang, 2011; Choi et al, 2017)。比如, 最近的大规模基因组分析结果表明, 普通野生稻种群广泛受到栽培稻的基因流的影响, 现存普通野生稻实际上是野-栽杂种群(hybrid swarm) (Wang et al, 2017)。这意味着, 用现存普通野 生稻为参照进行遗传关系分析时, 很难排除栽培稻 基因流的干扰。稻作强度越大地区的野生稻种群受 到栽培稻基因渐渗(introgression)的影响越大，遗传 上与栽培稻的关系也更近, 导致可能出现起源地的 误判。充分利用考古发现的水稻实物遗存, 结合古 


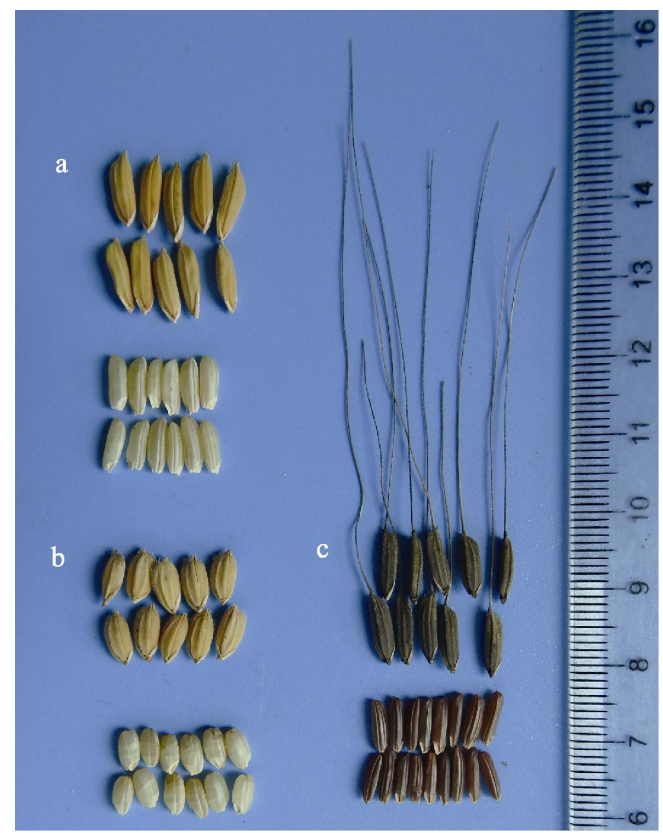

图1 普通野生稻、籼稻、粳稻的谷粒及种子形态。a: 籼稻 9311; b: 粳稻日本晴(Nipponbare); c: 普通野生稻(来自江 西东乡)

Fig. 1 Grain and seed of Oryza rufipogon, O. sativa ssp. indica and japonica. a, indica variety 9311; b, japonica variety Nipponbare; c, O. rufipogon from Dongxiang population of Jiangxi Province.

DNA分析(如Castillo et al, 2016), 能够降低栽培稻 基因流的干扰，从而获得更加可信的结果。

\section{3 水稻起源于长江流域的考古证据}

据Silva等(2015)统计，世界各地已发现的涉及 亚洲栽培稻的水稻遗址共有 470 多处，其中约 $1 / 3$ 分 布在中国。Gong等(2007)认为中国共有280处水稻文 物遗址。公婷婷(2017)对我国水稻考古遗址重新进 行了较全面的梳理, 认为有明确的实物遗存的水稻 遗址为219处。通过对上述资料进行比对和重新统 计相关资料，我们共获得了 328 处中国的水稻考古 遗址信息，按照年代进行等级划分，制作了中国古 稻分布图(图2)。这些水稻遗址空间分布格局、出土 的植物遗存和其他文物类型的变迁，大致反映了水 稻驯化起源与扩散的历史脉络，以及稻作农业的形 成与稻作文明的发展与传播历程。

在中国，早于 8,000 年的水稻遗址共有 16 处，除 了广东的牛栏洞遗址 $\left(113.45^{\circ} \mathrm{E}, 24.33^{\circ} \mathrm{N}\right)$ 和河南的 贾湖遗址 $\left(113.70^{\circ} \mathrm{E}, 33.62^{\circ} \mathrm{N}\right)$ 外，其余 14 处遗址全 部位于长江流域(图2)，其中包括了世界上最古老的 三个水稻遗址，即江西省万年县的仙人洞遗址 $\left(117.179^{\circ} \mathrm{E}, 28.721^{\circ} \mathrm{N}\right)$ 和吊桶环遗址 $\left(117.178^{\circ} \mathrm{E}\right.$, $\left.28.721^{\circ} \mathrm{N}\right)$ 、湖南省道县的玉蟾岩遗址 $\left(115.00^{\circ} \mathrm{E}\right.$, $\left.25.50^{\circ} \mathrm{N}\right)$ 。这三处遗址都处于长江中游, 均是洞穴 遗址，年代为旧石器时代晚期向新石器时代早期的

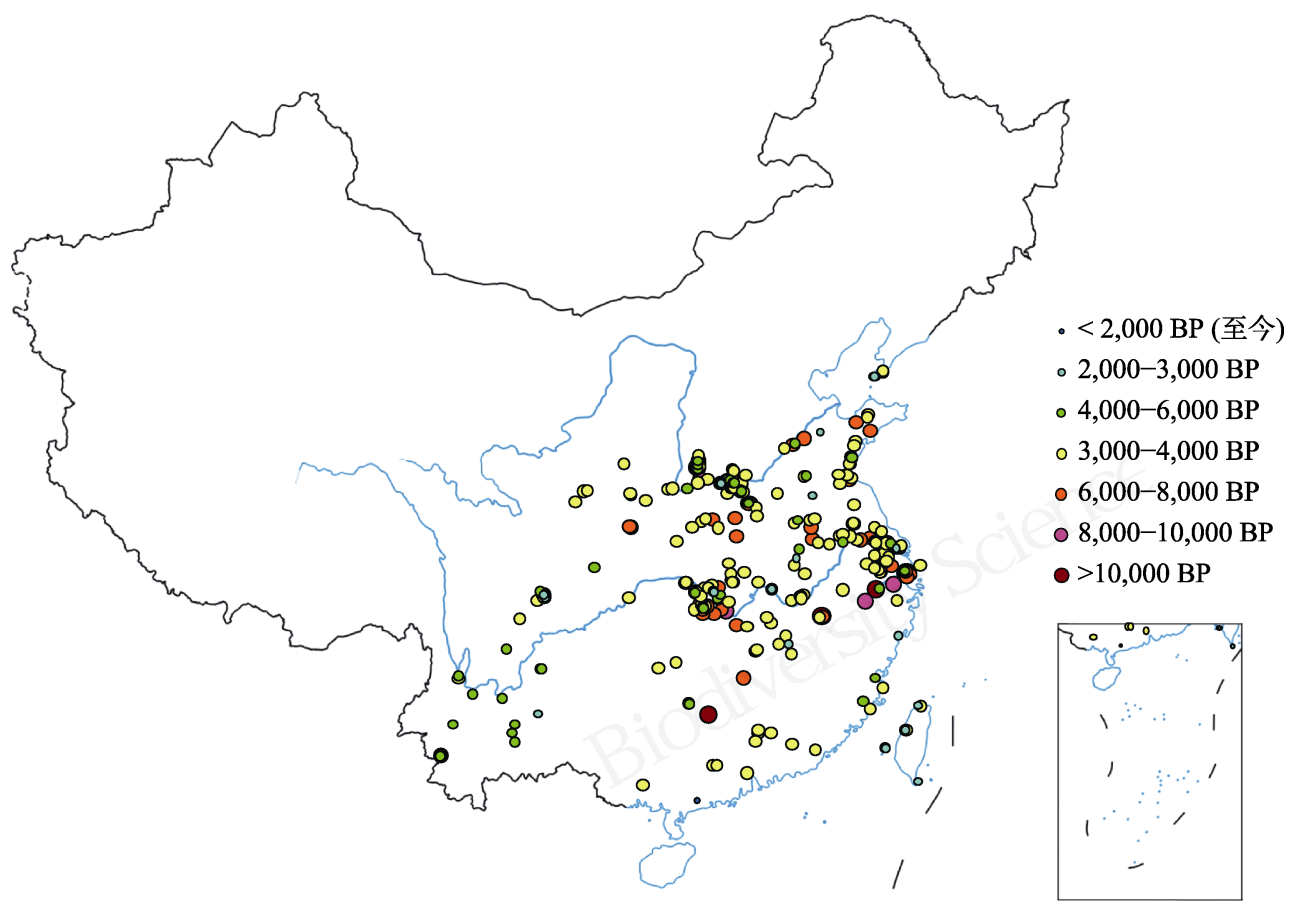

图2 中国水稻遗址时空分布图

Fig. 2 The temporal and spatial distribution of ancient rice relics in China 
过渡时期(约13,000-11,000 BP) (赵志军, 2009; Wu et al, 2012)。仙人洞与吊桶环相邻, 遗址内旧石器时 代晚期的地层中发现了野生稻的植硅石(phytolith), 而在新石器时代初期的地层中则发现了栽培稻的 植硅石，年代距今 1 万年以前(Zhao，1998)。植硅石 是指细胞组织中的蛋白石体 $\left(\mathrm{SiO}_{2} \cdot \mathrm{nH}_{2} \mathrm{O}\right)$, 可以在土 壤中保留相当长的一段时间。不同植物的植硅石形 态上存在差异，比如粳稻的扇形植硅石为“厚而尖” 的 $\beta$ 型，籼稻则是 “薄而圆” 的 $\alpha$ 型，而普通野生稻植 硅石的特征介于粳稻、籼稻之间, 因而常常被用于 水稻考古研究(Zuo et al, 2017)。玉蟾岩遗址不仅出 土了一粒极为珍贵的、形态与普通野生稻相似但无 芒的稻壳, 而且还出土了掺有稻秆和谷壳的贴塑法 成型的夹炭陶(张文续和袁家荣, 1998)。在稻作农业 地区, 夹炭陶常常与古稻伴生出土, 而不从事稻作 农业生产的地方往往只有夹砂陶。玉蟾岩的贴塑法 成型工艺, 被认为是后代贴塑法工艺的开山鼻祖, 也是稻作农业发祥的重要佐证材料之一(赵志军, 2009)。

接下来较古老的水稻遗址是上山遗址 $(11,000-9,000$ BP $)\left(119.89^{\circ} \mathrm{E}, 29.52^{\circ} \mathrm{N}\right)$ 和荷花山遗 址 $(10,000-9,000 \mathrm{BP})\left(119.30^{\circ} \mathrm{E}, 29.06^{\circ} \mathrm{N}\right)$ 。上山遗 址出土了结构比较完整的木构建筑基址、灰坑、石 器、陶器、骨器等文物, 特别引人注目的是出土了 几十粒炭化稻米和少量稻穗基盘, 以及含有稻谷颖 壳的碎陶片和烧制土残块。这些水稻遗存从稻谷的 大小、小穗基盘的形态和植硅石类型上来看，属于 早期的栽培稻(Jiang \& Liu, 2006; 郑云飞和蒋乐平, 2007; 赵志军和蒋乐平, 2016)。对上山考古点出土 的植物遗存的植硅石和淀粉微化石的进一步分析 显示, 除了水稻之外, 稗草在当地大量出现, 其次 还有橡实和菱角, 这说明当时的先人最初管理湿地 环境是为了收获包括水稻和稗子在内的禾草植物 的籽粒, 同时也暗示水稻是比较容易栽培的禾草而 逐渐被驯化利用(Yang et al, 2015)。Zuo等(2017)对 上山遗址和荷花山遗址的古稻的植硅石进行了比 较分析, 发现从9,400-8,600 BP, 古稻的驯化程度在 逐步加强, 但驯化速度缓慢, 进一步确认水稻开始 驯化的年代大致在距今约1万年前后的全新世早期, 也表明我国长江流域水稻驯化与世界上其他主要 农作物(西亚的小麦、中美洲的玉米)驯化基本上是 同步的，都发生在更新世末向全新世初过渡的时期，
这与当时逐渐变暖、变湿的全球气候格局转变有密 切的关系。

从距今 9,000年开始, 稻作遗址逐渐増多(图2), 遗址中稻作遗存所处年代也更为确切, 比如长江中 游地区的属于彭头山文化 $(9,000-8,300 \mathrm{BP})$ 的八十 垱 $\left(111.85^{\circ} \mathrm{E}, 29.76^{\circ} \mathrm{N}\right)$ 、彭头山 $\left(111.65^{\circ} \mathrm{E}, 29.66^{\circ} \mathrm{N}\right)$ 和宋家岗遗址 $\left(111.78^{\circ} \mathrm{E}, 29.72^{\circ} \mathrm{N}\right)$, 长江下游地区 的小黄山遗址 $\left(120.73^{\circ} \mathrm{E}, 29.55^{\circ} \mathrm{N}\right)$ 等。八十垱遗址 出土了距今 $8,500-7,500$ 年的数万粒完整形态的炭 化稻谷、稻米, 还有环绕聚落的围墙、挡水坝，以 及大量的墓葬和以杆栏式建筑为主的居住房址, 还 有大量的陶器、石器、骨器、木器、百余种植物杆 茎与果核等。这些古稻从形态上具有原始性和过渡 性的特征，属于未经人工选择的原始栽培稻类型 (赵笃乐等, 2000)。最近的植物考古分析显示, 在人 类定居之前(大约8,600年前), 八十垱所在地区为泛 滥平原，随后因全新世季风降水增多，水位上升， 逐渐变成湿地, 辅以火烧和简单清理, 这些都有利 于水稻栽培, 使得水稻驯化在该地区持续兴盛了数 百年(Liu et al, 2017)。宋家岗遗址出土了距今约 9,000 年的 100 多粒炭化稻米, 这些稻米集中分布在 一处面积约 4-5 $\mathrm{m}^{2}$ 的生活区，紧邻一处灶坑，同时 伴出大量夹有谷粒与稻壳的陶片, 少量石制品等生 活用器, 人类食用水稻的痕迹明显(赵志军, 2009)。 彭头山遗址出土的陶器制造古朴简单，全部为原始 的贴塑法制成, 大部分陶器的胎泥中夹有炭屑, 部 分含有稻壳与谷粒或稃壳印痕。张文绪等(2003)用 扫描电镜对这些陶片中的水稻稃壳印痕进行分析 后认为, 这些古稻形态上已向粳稻演化。同样, 植 硅石和颖壳双峰乳突的形态分析结果表明，小黄山 古稻属于原始栽培稻，而且有向粳稻演化的趋势 (郑云飞等, 2013)。以上这些考古证据表明，一方面 我国长江流域在更新世晚期至全新世早期有野生 稻分布, 另一方面栽培稻在 10,000 BP左右开始出 现，尽管当时的生计形态仍处在采集狩猎阶段(赵 志军, 2009; 公婷婷, 2017)。

随着时间推移，中国的古稻遗址迅速增多， 8,000-6,000 BP的水稻遗址有62处, 其中 35 处位于 长江流域, 例如, 8,000-7,000 BP的位于长江下游的 跨湖桥遗址 $\left(120.26^{\circ} \mathrm{E}, 30.18^{\circ} \mathrm{N}\right)$ 等。跨湖桥遗址位 于浙江省萧山, 出土的植物遗存包括水稻、菱角、 苂实等。该遗址出土的稻谷经过鉴定, 60\%为野生稻, 
40\%属于栽培稻(郑云飞等, 2004; 郑云飞和蒋乐平, 2007)。跨湖桥遗址还出现了专门用于煮米饭的蒸锅 “薯”, 显示米饭在食物中的地位开始提升。到了 7,000-6,000 BP, 遗址古稻以栽培型为主, 既有粳型 或向粳稻方向发展，又有偏粳、偏籼混合或者偏粳、 偏籼和中间型混合。河姆渡遗址 $\left(121.30^{\circ} \mathrm{E}, 29.98^{\circ}\right.$ N)距今 7,000-5,800年间, 位于浙江余姚市, 出土了 丰富的植物遗存，包括稻谷、栎果、菱角、苂实等 可食用植物遗存, 特别是大量的稻谷遗存, 显示河 姆渡文化已经发展到了较发达的稻作农业生产阶 段(刘军, 2006; 赵志军, 2009)。田螺山遗址(121.40 E, $30.04^{\circ} \mathrm{N}$ ) 也位于浙江省余姚市, 距今年代约为 $7,000-5,500$ 年间，出土的食用植物包括稻谷、菱角、 苂实、橡实，还出土了木质和骨质的锄和锹等农业 用具。Fuller等(2009)分析了田螺山6,900-6,600年前 的土层中的植物遗存类型及水稻小穗基盘形态, 发 现在此300年间，植物遗存中水稻遗存的比例从 $8 \%$ 上升到 24\%, 不落粒的栽培稻小穗基盘的比例从 $27 \%$ 上升到 $39 \%$, 稻田杂草如一年生的禾草、莎草和 其他草本植物呈现聚集趋势, 这些都说明水稻的消 费比例上升, 稻谷驯化正在不断加强, 出现了水稻 种植。此外, 田螺山还发现了距今约7,000-4,500年 的稻田。以上这些考古发现充分说明, 即使当时种 植水稻的水平可能很低, 食物还大量依赖于采集和 狩猎，但稻作农业开始形成(赵志军, 2009)。

到了6,000-4,000 BP, 水稻遗址进一步增多, 共 有178处, 其中近80处在长江流域。这些遗址出土了 大量的水稻实物遗存, 以及生产、生活用具等文物, 充分反映了当时水稻广泛栽培与稻作农业快速发 展的情景。这一时期, 长江流域的各遗址古稻基本 上都表现为偏粳型, 比如城头山古稻。城头山遗址 (6,000-5,000 BP) $\left(111.60^{\circ} \mathrm{E}, 29.82^{\circ} \mathrm{N}\right)$ 位于湖南省 常德市澧县, 以出土时代最早、保存最完整的古城 和灌溉设施完备的稻田而闻名。该遗址出土了稻、 瓜等170多种人工种植和野生植物的籽粒，以及猪、 羊、狗、鹿等20多种家养和野生动物骨骸。稻谷粒 形分析显示, 城头山古稻种群中含有类似野生稻粒 形的个体仅占5.59\%, 94\%以上为栽培稻粒形(张文 绪和顾海滨，2005)。这些证据表明，在当时水稻驯 化业已完成, 稻作农业体系已经建立, 稻作文明已 经形成(赵志军, 2009; Fuller et al, 2010; Gross \& Zhao, 2015)。
到了新石器时代后期(5,000-4,000 BP), 长江流 域的水稻考古遗址数量剧增, 反映出稻作农业生产 体系的发展与传播与当时人口大幅度增长的密切 关系。例如, 在长江下游的杭州湾地区和太湖流域, 距今 5,200-4,300年间的良渚文化时期的遗址的分 布异常密集(图2)。同样，在长江中游地区也发现了 大量距 今 5,300-4,600 年间的屈家岭 $\left(113.12^{\circ} \mathrm{E}\right.$, $31.02^{\circ} \mathrm{N}$ )文化时期和距今 4,600-4,000年间的石家 河 $\left(113.09^{\circ} \mathrm{E}, 30.76^{\circ} \mathrm{N}\right)$ 文化时期的稻作遗址群。这 些遗址出土的文物和动植物遗存充分说明, 稻作农 业已经取代采集狩猎成为当地经济的主体。同一时 期，在邻近长江流域的淮河流域、黄河流域甚至更 北地区也涌现出大量的水稻遗址(图2), 反映了水稻 自驯化起源之地一一长江流域向外辐射与传播, 标 志着稻作文明的快速发展。

4,000 BP以后, 古稻遗址以长江中下游为中心, 向北、向西、向南辐射，展示了稻作文明繁荣与传 播的图景。这些遗址古稻(包括来自长江流域的)基 本上属于粳型，而且与现代粳稻类型基本一致(公 婷婷, 2017)。

\section{稻作的起源与发展催生了长汀文}

遗传学研究关于水稻(粳稻)的最早起源的具体 地点是长江流域还是珠江流域尚存在争议，但可以 概括为: 水稻最先起源于长江流域及以南地区 (珠 江流域)。同时, 大量的考古学证据表明水稻于 10,000-8,000 BP在长江流域开始驯化(Cross \& Zhao, 2014)。长江流域考古遗址中的古稻类型随年代下降 逐渐转变为栽培稻类型(粳稻类型)。伴随着此过程, 长江流域出现了一脉相承但有其特色的史前文明, 尤其是长江中游的农耕发展, 自彭头山以降, 经过 皇市下层 $\left(111.40^{\circ} \mathrm{E}, 29.65^{\circ} \mathrm{N}\right)$ 、汤家岗 $\left(112.17^{\circ} \mathrm{E}\right.$, $\left.29.41^{\circ} \mathrm{N}\right)$ 、大溪 $\left(109.63^{\circ} \mathrm{E}, 30.98^{\circ} \mathrm{N}\right)$ 、屈家岭、石 家河等连续发展出来的文化，表现出了完整的进步 过程, 到新石器中期的汤家岗文化, 已表现出相当 成熟的农业文明形态(郭静云和郭立新, 2014)。这个 发展过程体现在诸多方面。首先，出土文物中盛物 用具和耕作工具逐渐增多，而且越来越高级。从玉 蟾岩遗址的最原始的夹炭陶，到河姆渡文化时期 (罗家角遗址)的白陶，再到大溪文化 $(7,500-5,000$ $\mathrm{BP})$ 与屈家岭文化 (5,000-4,000 BP)时期的黑陶; 从 原始粗粘的旧石器, 到精小石器, 发展到石质、骨 
质与木质器具(如河姆渡文化时期), 再到未耤出现, 最后出现铜器、铁器; 从最早的刀耕水浱农业到耤 耕农业、再到犁耕农业(刘军, 2006; Fuller, 2011)。 其次, 生活方式变迁。居住点从洞穴, 到台地, 再到 聚落, 发展至城邦; 活动方式从迁徙, 到季节性迁 徙, 到定居(郭静云和郭立新, 2014)。第三, 生业经 济从狩猎-采集, 到照顾植物与狩猎采集并重, 再 到栽培植物为主, 进而养殖动植物的农业(赵志军, 2009)。第四, 从直接利用湿地到雨浇地, 发展到具 有排灌设施的稻田系统, 如城头山遗址(张文绪和 顾海滨, 2005)。制陶技艺、犁耕农业、排灌系统、 城邦、古老的宗教与艺术(如高庙文化, 7,800-6,800 BP)等都是长江文明的重要符号, 它们的发展或出 现无疑都是稻作农业发展的必然产物。因此, 可以 说是稻作的起源与发展催生了长江文明, 长江文明 以稻作文明为核心。

\section{5 研究展望}

尽管关于水稻起源问题, 考古学和遗传学研究 得出的结论总体趋于一致, 但仍有争议。第一, 考 古学证据明确显示长江流域是水稻的最早起源地 (Silva et al, 2015), 而且考古学研究结果还显示, 农 业大约在 2,700 BP才开始进入珠江流域(Hu et al, 2013), 但部分遗传学研究结果则倾向于水稻起源 于珠江流域(如Huang et al, 2012b; Wei et al, 2012)。 第二, 考古学估计的水稻起源时间 ( 10,000 BP) 明 显近于遗传学研究基于分子钟估算的时间 (一 般>13,000 BP) (Jones \& Liu, 2009)。未来采用更加灵 敏的分析技术，比如建立水稻遗存物的古DNA高效 提取与分析技术体系，或者是单粒古孢粉测序技术， 有望消除栽培稻基因流对分析结果的干扰，从而追 溯水稻驯化过程中的遗传变化。

当前, 长江流域的野生稻分布点很少, 但大量 的古稻遗址位于长江流域及以北地区。这种格局暗 示, 历史气候变化和长期的生境利用引起野生稻分 布区向南收缩。当前, 长江流域是人类活动强度最 大的地区之一。这种高强度的人类活动如何影响以 野生稻为代表的重要资源植物的进化过程, 依然知 之甚少。进行古气候、古植被、土壤地层学和考古 学等资料的整合分析, 将有助于探讨此问题, 其结 果对于植物遗传资源的保护也有启示意义。

\section{参考文献}

Asano K, Yamasaki M, Takuno S, Miura K, Katagiri S, Ito T, Doi K, Wu JZ, Ebana K, Matsumoto T, Innan H, Kitano H, Ashikari M, Matsuoka M (2011) Artificial selection for a green revolution gene during japonica rice domestication. Proceedings of the National Academy of Sciences, USA, 108, 11034-11039.

Barton L, Newsome SD, Che FH, Wang H, Guilderson TP, Bettinger RL (2009) Agricultural origins and the isotopic identity of domestication in northern China. Proceedings of the National Academy of Sciences, USA, 106, 5523-5528.

Caicedo AL, Williamson SH, Hernandez RD, Boyko A, Fledel-Alon A, York TL, Polato NR, Olsen KM, Nielsen R, McCouch SR (2007) Genome-wide patterns of nucleotide polymorphism in domesticated rice. PLoS Genetics, 3, 1745-1756.

Castillo CC, Tanaka K, Sato YI, Ishikawa R, Bellina B, Higham C, Chang N, Mohanty R, Kajale M, Fuller DQ (2016) Archaeogenetic study of prehistoric rice remains from Thailand and India: Evidence of early japonica in South and Southeast Asia. Archaeological and Anthropological Science, 8, 523-543.

Choi JY, Platts AE, Fuller DQ, Hsing YL, Wing RA, Purugganan MD (2017) The rice paradox: Multiple origins but single domestication in Asian rice. Molecular Biology and Evolution. 34, 969-979.

Choi JY, Purugganan MD (2018) Multiple origin but single domestication led to Oryza sativa. G3-Genes Genomes Genetics, 8, 797-803.

Civáň P, Brown TA (2017) Origin of rice (Oryza sativa L.) domestication genes. Genetic Resources and Crop Evolution, 64, 1125-1132.

Civáň P, Craig H, Cox CJ, Brown TA (2015) Three geographically separate domestications of Asian rice. Nature Plants, 1, 15164.

Cohn MA, Butera DL, Hughes JA (1983) Seed dormancy in red rice. III. Response to nitrite, nitrate, and ammonium ions. Plant Physiology, 73, 381-384.

Cross BL, Zhao ZJ (2014) Archaeological and genetic insights into the origins of domesticated rice. Proceedings of the National Academy of Sciences, USA, 111, 6190-6197.

Fuller DQ (2007) Contrasting patterns in crop domestication and domestication rates: Recent archaeobotanical insights from the Old World. Annals of Botany (London), 100, 903-924.

Fuller DQ (2011) Pathways to Asian civilizations: Tracing the origins and spread of rice and rice cultures. Rice, 4, 78-92.

Fuller DQ, Qin L, Harvey E (2008) Rice archaeobotany revisted. Antiquity, 82, 315.

Fuller DQ, Qin L, Zheng YF, Zhao ZJ, Chen XG, Hosoya LA, Sun GP (2009) The domestication process and domestication rate in rice: Spikelet bases from the Lower Yangtze. 
Science, 323, 1607-1610.

Fuller DQ, Sato YI, Castillo C, Qin L, Weisskopf AR, Kingwell-Banham EJ, Song JX, Ahn SM, van Etten J (2010) Consilience of genetics and archaeobotany in the entangled history of rice. Archaeological and Anthropological Science, 2, 115-131.

Gao LZ, Innan H (2008) Nonindependent domestication of the two rice subspecies, Oryza sativa ssp. indica and ssp. japonica, demonstrated by multilocus microsatellites. Genetics, 179, 965-976.

Garris AJ, Tai TH, Coburn J, Kresovich S, McCouch S (2005) Genetic structure and diversity in Oryza sativa L. Genetics, 169, 1631-1638.

Ge S, Sang T (2011) In appropriate model rejects independent domestications of indica and japonica rice. Proceedings of the National Academy of Sciences, USA, 108, E755.

Gong TT (2017) Origin, domestication and dispersal of Chinese Cultivated Rice. PhD dissertation, Minzu University of China, Beijing. (in Chinese with English abstract) [公婷婷 (2017) 中国水稻的起源、驯化及传播研究. 博士学位论 文，中央民族大学，北京.]

Gong ZT, Chen HZ, Yuan DG, Zhao YG, Wu YJ, Zhang GL (2007) The temporal and spatial distribution of ancient rice in China and its implications. Chinese Science Bulletin, 52, 1071-1079.

Gross BL, Zhao ZJ (2014) Archaeological and genetic insights into the origins of domesticated rice. Proceedings of the National Academy of Sciences, USA, 111, 6190-6197.

Gu XY, Foley ME, Horvath DP, Anderson JV, Feng JH, Zhang LH, Mowry CR, Ye H, Suttle JC, Kadowaki K, Chen ZX (2011) Association between seed dormancy and pericarp color is controlled by a pleiotropic gene that regulates abscisic acid and flavonoid synthesis in weedy red rice. Genetics, 189, 1515-1524.

Guo JY, Guo LX (2014) The origin and formation of rice cultivation: Spatio-temporal parameters. Agricultural History of China, 5, 3-13. (in Chinese) [郭静云, 郭立新 (2014) 论稻 作萌生与成熟的时空问题. 中国农史, 5, 3-13.]

Hammer K (1984) The domestication syndrome. Genetic Resources and Crop Evolution, 32, 11-34.

He ZW, Zhai WW, Wen HJ, Tang T, Wang Y, Lu XM, Greenberg AJ, Hudson RR (2011) Two evolutionary histories in the genome of rice: The roles of domestication genes. PLoS Genetics, 7, e1002100.

Hu DK, Clift PD, Böning P, Hannigan R, Hillier S, Blusztajn J, Wan SM, Fuller DQ (2013) Holocene evolution in weathering and erosion patterns in the Pearl River delta. Geochemistry Geophysics Geosystems, 14, 2349-2368.

Huang P, Molina J, Flowers JM, Rubinstein S, Jackson SA, Purugganan MD, Schaal BA (2012a) Phylogeography of Asian wild rice, Oryza rufipogon: A genome-wide view. Molecular Ecology, 21, 4593-4604.

Huang P, Schaal BA (2012) Association between the geo- graphic distribution during the last glacial maximum of Asian wild rice, Oryza rufipogon (Poaceae), and its current genetic variation. American Journal of Botany, 99, 1866-1874.

Huang XH, Kurata N, Wei X, Wang ZX, Wang A, Zhao Q, Zhao Y, Liu KY, Lu HY, Li WJ (2012b) A map of rice genome variation reveals the origin of cultivated rice. Nature, 490, 497-501.

Jiang LP, Liu L (2006) New evidence for the origins of sedentism and rice domestication in the Lower Yangtze River, China. Antiquity, 80, 355-361.

Jin J, Huang W, Gao JP, Yang J, Shi M, Zhu MZ, Luo D, Lin HX (2008) Genetic control of rice plant architecture under domestication. Nature Genetics, 40, 1365-1369.

Jones MK, Liu XY (2009) Archaeology: Origins of agriculture in East Asia. Science, 324, 730-731.

Khush GS (1997) Origin, dispersal, cultivation and variation of rice. Plant Molecular Biology, 35, 25-34.

Konishi S, Izawa T, Lin SY, Ebana K, Fukuta Y, Sasaki T, Yano M (2006) An SNP caused loss of seed shattering during rice domestication. Science, 312, 1392-1396.

Kovach MJ, Sweeney MT, McCouch SR (2007) New insights into the history of rice domestication. Trends in Genetics, 23, 578-587.

Larson G, Piperno DR, Allaby RG, Purugganan MD, Andersson L, Arroyo-Kalin M, Barton L, Vigueira CC, Denham T, Dobney K (2014) Current perspectives and the future of domestication studies. Proceedings of the National Academy of Sciences, USA, 111, 6139-6146.

Li CB, Zhou AL, Sang T (2006) Rice domestication by reducing shattering. Science, 311, 1936-1939.

Lin ZW, Griffith ME, Li XR, Zhu ZF, Tan LB, Fu YC, Zhang WX, Wang XK, Xie DX, Sun CQ (2007) Origin of seed shattering in rice (Oryza sativa L.). Planta, 226, 11-20.

Liu J (2006) Hemudu Culture. Cultural Relics Press, Beijing (in Chinese) [刘军 (2006) 河姆渡文化. 文物出版社, 北京.]

Liu R, Zheng XM, Zhou L, Zhou HF, Ge S (2015) Population genetic structure of Oryza rufipogon and Oryza nivara: Implications for the origin of O. nivara. Molecular Ecology, 24, 5211-5228.

Liu T, Liu Y, Sun QL, Zong YQ, Finlayson B, Chen ZY (2017) Early Holocene groundwater table fluctuations in relation to rice domestication in the middle Yangtze River basin, China. Quaternary Science Reviews, 155, 79-85.

Londo JP, Chiang YC, Hung KH, Chiang TY, Schaal BA (2006) Phylogeography of Asian wild rice, Oryza rufipogon, reveals multiple independent domestications of cultivated rice, Oryza sativa. Proceedings of the National Academy of Sciences, USA, 103, 9578-9583.

McNally KL, Childs KL, Bohnert R, Davidson RM, Zhao K, Ulat VJ, Zeller G, Clark RM, Hoen DR, Bureau TE (2009) Genomewide SNP variation reveals relationships among landraces and modern varieties of rice. Proceedings of the 
National Academy of Sciences, USA, 106, 12273-12278.

Molina J, Sikora M, Garud N, Flowers JM, Rubinstein S, Reynolds A, Huang P, Jackson S, Schaal BA, Bustamante CD, Boyko AR, Purugganan MD (2011) Molecular evidence for a single evolutionary origin of domesticated rice. Proceedings of the National Academy of Sciences, USA, 108, 8351-8356.

Ou SJ, Wang HR, Chu CC (2012) Major domestication traits in Asian rice. Hereditas (Beijing), 34, 1379-1389. (in Chinese with English abstract) [区树俊, 汪鸿儒, 储成才 (2012) 亚洲栽培稻主要驯化性状研究进展。遗传, 34, 1379-1389.]

Paterson AH, Li ZK (2011) Paleo-green revolution for rice. Proceedings of the National Academy of Sciences, USA, 108, 10931-10932.

Sakuma S, Salomon B, Komatsuda T (2011) The domestication syndrome genes responsible for the major changes in plant form in the Triticeae crops. Plant Cell Physiology, 52, 738-749.

Sang T, Ge S (2007) Genetics and phylogenetics of rice domestication. Current Opinion in Genetics \& Development, 17, 533-538.

Second G (1982) Origin of the genetic diversity of cultivated (Oryza spp.) study of the polymorphism scored at 40 isozyme loci. Japan Journal of Genetics, 57, 25-37.

Seshu DV, Dadlani M (1991) Mechanism of seed dormancy in rice. Seed Scicene Research, 1, 187-194.

Shomura A, Izawa T, Ebana K, Ebitani T, Kanegae H, Konishi S, Yano M (2008) Deletion in a gene associated with grain size increased yields during rice domestication. Nature Genetics, 40, 1023-1028.

Silva F, Stevens CJ, Weisskopf A, Castillo C, Qin L, Bevan A, Fuller DQ (2015) Modelling the geographical origin of rice cultivation in Asia using the rice archaeological database. PLoS ONE, 10, e0137024.

Singh N, Singh B, Rai V, Sidhu S, Singh AK, Singh NC (2017) Evolutionary insights based on SNP haplotypes of red pericarp, grain size and starch synthase genes in wild and cultivated rice. Frontiers in Plant Science, 8, 972.

Song ZP, Zhu WY, Rong J, Xu X, Chen JK, Lu BR (2006) Evidences of introgression from cultivated rice to Oryza rufipogon (Poaceae) populations based on SSR fingerprinting: Implications for wild rice differentiation and conservation. Evolutionary Ecology, 20, 501-522.

Sun CQ, Wang XK, Yoshimura A, Iwata N (1997) RFLP analysis of nuclear DNA in common wild rice (Oryza rufipogon Griff.) and cultivated rice (Oryza sativa L.). Scientia Agricultura Sinica, 30, 37-44.

Sweeney M, McCouch S (2007) The complex history of the domestication of rice. Annals of Botany, 100, 951-957.

Sweeney MT, Thomson MJ, Cho YG, Park YJ, Williamson SH, Bustamante CD, McCouch SR (2007) Global dissemination of a single mutation conferring white pericarp in rice.
PLoS Genetics, 3, e133.

Tan LB, Li XR, Liu FX, Sun XY, Li CG, Zhu ZF, Fu CY, Cai HW, Wang XK, Xie DX, Sun CQ (2008) Control of a key transition from prostrate to erect growth in rice domestication. Nature Genetics, 40, 1360-1364.

Tang T, Lu J, Huang JZ, He JH, McCouch SR, Shen Y, Kai Z, Purugganan MD, Shi SH, Wu CI (2006) Genomic variation in rice: genesis of highly polymorphic linkage blocks during domestication. PLoS Genetics, 2, 1824-1833.

Vaughan DA, Ge S, Kaga A, Tomooka N (2008a) Phylogeny and biogeography of the genus Oryza. In: Rice Biology in the Genomics Era (eds Hirano HY, Hirai A, Sano Y, Sasaki T), pp 219-231. Springer-Verlag, Berlin, Heidelberg.

Vaughan DA, Lu BR, Tomooka N (2008b) Was Asian rice (Oryza sativa) domesticated more than once? Rice, 1, 16-24.

Vaughan DA, Morishima H, Kadowaki K (2003) Diversity in the Oryza genus. Current Opinion in Plant Biology, 6, 139-146.

Vitte C, Ishii T, Lamy F, Brar D, Panaud O (2004) Genomic paleontology provides evidence for two distinct origins of Asian rice (Oryza sativa L.). Molecular Genetics and Genomics, 272, 504-511.

Wang H, Vieira FG, Crawford JE, Chu CC, Nielsen R (2017) Asian wild rice is a 477 hybrid swarm with extensive gene flow and feralization from domesticated rice. Genome Research, 27, 1029-1038.

Wang XK (1996) New research progresses relating to several main problems about the origin of rice cultivation in China. In: Origin and Differentiation of Chinese Cultivated Rice (eds Wang XK, Sun CQ), pp. 2-7. China Agricultural University Press, Beijing. (in Chinese with English abstract) [王 象坤 (1996) 中国稻作起源研究中几个主要问题的研究 新进展. 见: 中国栽培稻起源与演化研究专集(王象坤, 孙传清编), 2-7页. 中国农业大学出版社, 北京.]

Wang YH, Li JY (2005) The plant architecture of rice (Oryza sativa). Plant Molecular Biology, 59, 75-84.

Wei X, Qiao WH, Chen YT, Wang RS, Cao LR, Zhang WX, Yuan NN, Li ZC, Zeng HL, Yang QW (2012) Domestication and geographic origin of Oryza sativa in China: Insights from multilocus analysis of nucleotide variation of $O$. sativa and O. rufipogon. Molecular Ecology, 21, 5073-5087.

Wu XH, Zhang C, Goldberg P, Cohen D, Pan Y, Arpin T, Bar-Yosef O (2012) Early pottery at 20,000 years ago in Xianrendong Cave, China. Science, 336, 1696-1700.

Yang XY, Fuller DQ, Huan XJ, Perry L, Li Q, Li Z, Zhang JP, Ma ZK, Zhuang YJ, Jiang LP, Ge Y, Lu HY (2015) Barnyard grasses were processed with rice around 10000 years ago. Scientific Reports, 5, 16251.

Zhang LB, Zhu QH, Wu ZQ, Ross-Ibarra J, Gaut BS, Ge S, Sang $T$ (2009) Selection on grain shattering genes and rates of rice domestication. New Phytologist, 184, 708-720.

Zhang WX, Gu HB (2005) Study of ancient rice from Cheng- 
toushan site in Lixian County, Hunan Province. Acta Agronomica Sinica, 31, 736-741. (in Chinese with English abstract) [张文绪, 顾海滨 (2005) 湖南澧县城头山遗址 古稻研究. 作物学报, 31, 736-741.]

Zhang WX, Pei AP, Mao TL (2003) Studies on the printings of bi-peaked tubercles on lemmas of rice kernels in broken pottery pieces unearthed from Pengtoushan excavation site in Li County, Hunan. Acta Agronomica Sinica, 29, 263-267. (in Chinese with English abstract) [张文绪, 裴安 平, 毛同林 (2003) 湖南澧县彭头山遗址陶片中水稻稃 壳双峰乳突印痕的研究. 作物学报, 29, 263-267.]

Zhang WX, Yuan JR (1998) Primary study of ancient rice from Yuchanyan site in Daoxian County, Hunan Province. Acta Agronomica Sinica, 24, 416-420. (in Chinese with English abstract) [张文续, 袁家荣 (1998) 湖南道县玉蟾岩古栽 培稻的初步研究. 作物学报, 24, 416-420.]

Zhao DL, Pei AP, Zhang WX (2000) Restudy of ancient cultivated rice from Bashidang site in Lixian County, Hunan Province. Chinese Journal of Rice Sicence, 14(3), 139-143. (in Chinese with English abstract) [赵笃乐, 裴安平, 张文 绪 (2000) 湖南澧县八十垱遗址古栽培稻的再研究. 中 国水稻科学, 14(3), 139-143.]

Zhao KY, Wright M, Kimball J, Eizenga G, McClung A, Kovach M, Tyagi W, Ali ML, Tung CW, Reynolds A, Bustamante CD, McCouch SR (2010) Genomic diversity and introgression in O. sativa reveal the impact of domestication and breeding on the rice genome. PLoS ONE, 5, e10780.

Zhao Y, Vrieling K, Liao H, Xiao MQ, Zhu YQ, Rong J, Zhang WJ, Wang YG, Yang J, Chen JK, Song ZP (2013) Are habitat fragmentation, local adaptation and isolation-by-distance driving population divergence in wild rice Oryza rufipogon? Molecular Ecology, 22, 5531-5547.

Zhao ZJ (1998) The middle Yangtze region in China is one place where rice was domesticated: Phytolith evidence from the Diaotonghuan cave, northern Jiangxi. Antiquity, 278, 885-897.

Zhao ZJ (2009) New informations and research advances about the origin of cultivated rice and rice agriculture. Southern Relics, 3, 59-63. (in Chinese) [赵志军 (2009) 栽培稻与稻
作农业起源研究的新资料和新进展. 南方文物, 3, 59-63.]

Zhao ZJ (2011) New archaeobotanic data for the study of the origins of agriculture in China. Current Anthropology, 52(S4), S295-S306.

Zhao ZJ, Jiang LP (2016) Analysis of plant relics from Shangshan site in Pujiang of Zhejiang. Southern Relics, 3, 109-116. (in Chinese with English abstract) [赵志军, 蒋乐 平 (2016) 浙江浦江上山遗址浮选出土植物遗存分析. 南方文物, 3, 109-116.]

Zheng YF, Chen XG, Wang HM (2013) Rice cultivation from Xiaohuangshan site in Shengzhou of Zhejiang Province, based on phytoliths analysis. Agricultural Archaeology, 4, 11-17. (in Chinese with English abstract) [郑云飞, 陈旭高, 王海明 (2013) 浙江嵊州小黄山遗址的稻作生产——来 自植物硅酸体的证据. 农业考古, 4, 11-17.]

Zheng YF, Jiang LP (2007) Rice relics from Shangshan site and its implications. Archaeology, 9, 19-25. (in Chinese with English abstract) [郑云飞, 蒋乐平 (2007) 上山遗址 出土的古稻遗存及其意义. 考古, 9, 19-25.]

Zheng YF, Jiang LP, Zheng JM (2004) Study on the remains of ancient rice from Kuahuqiao site in Zhejiang Province. Chinese Journal of Rice Science, 18(2), 119-124. (in Chinese with English abstract) [郑云飞, 蒋乐平, 郑建明 (2004) 浙江跨湖桥遗址的古稻遗存研究. 中国水稻科学, 18(2), 119-124.]

Zhu QH, Ge S (2005) Phylogenetic relationships among A-genome species of the genus Oryza revealed by intron sequences of four nuclear genes. New Phytologist, 167, 249-265.

Zong Y, Chen Z, Innes JB, Chen C, Wang Z, Wang H (2007) Fire and flood management of coastal swamp enabled first rice paddy cultivation in East China. Nature, 449, 459-462.

Zuo XX, Lu HY, Jiang LP, Zhang JP, Yang XY, Huan XJ, He KY, Wang W, Wu NQ (2017) Dating rice remains through phytolith carbon-14 study reveals domestication at the beginning of the Holocene. Proceedings of the National Academy of Sciences, USA, 114, 6486-6491.

(责任编委：杨庆文 责任编辑：时意专) 